\title{
Incêndio em edificações hospitalares: conhecimento dos profissionais de enfermagem sobre prevenção, combate e escape
}

Fires in hospital buildings: knowledge held by nursing professionals regarding prevention, combat and escape

Incendios en edificios hospitalarios: conocimiento de profesionales de enfermería sobre prevención, combate y escape

Renato Santiago Costa Rodrigues ${ }^{1}$, Ana Elisa Bauer de Camargo Silva ${ }^{2}$, Lizete Malagoni de Almeida Cavalcante Oliveira ${ }^{3}$, Virginia Visconde Brasil ${ }^{4}$, Katarinne Lima Moraes ${ }^{5}$, Jacqueline Andréia Bernardes Leão Cordeiro ${ }^{6}$

\footnotetext{
${ }^{1}$ Enfermeiro. Bombeiro Militar do Estado de Goiás. Goiânia, Goiás, Brasil. E-mail: renatohand@gmail.com.

${ }^{2}$ Enfermeira, Doutora em Enfermagem. Professora Adjunta da Faculdade de Enfermagem da Universidade Federal de Goiás (FEN/UFG). Goiânia, Goiás, Brasil. E-mail: anaelisa@terra.com.br.

${ }^{3}$ Enfermeira, Doutora em Ciências da Saúde. Professora Associada da FEN/UFG. Goiânia, Goiás, Brasil. E-mail: lizete.malagoni@gmail.com.

${ }^{4}$ Enfermeira, Doutora em Enfermagem. Professora Adjunta da FEN/UFG. Goiânia, Goiás, Brasil. E-mail: viscondebrasil@gmail.com.

${ }^{5}$ Enfermeira. Discente do Programa de Pós-Graduação em Enfermagem, Nível Mestrado, da FEN/UFG. Goiânia, Goiás, Brasil. E-mail: kateenf@gmail.com.

${ }^{6}$ Enfermeira, Mestre em Enfermagem. Discente do Programa de Pós-Graduação em Enfermagem, Nível Doutorado, da FEN/UFG Professora Assistente da FEN/UFG. Goiânia, Goiás, Brasil. E-mail: jackbl@uol.com.br.
}

\section{RESUMO}

Objetivou-se analisar o conhecimento e conduta dos profissionais da enfermagem acerca da prevenção, combate e escape de incêndios hospitalares. Estudo de caráter descritivo, foi realizado num hospital público de ensino, de Goiânia/GO, com 109 profissionais de enfermagem. Os dados foram coletados em 2011, por meio de entrevistas estruturadas com questionário e analisados por meio de estatística descritiva. A maioria entrevistada era do gênero feminino, técnicos/auxiliares de enfermagem $(67,9 \%)$, que conhecia o telefone do Corpo de Bombeiros $(85,3 \%)$ e onde estão extintores (80,7\%), mas não sabiam utilizá-los (69,7\%). A maior parte dos entrevistados não conhecia a rota de fuga (57,8\%) e, em caso de incêndio, acionaria bombeiros, orientaria as pessoas à saída, faria uso do extintor ou pularia janelas. As lacunas identificadas indicam necessidade de treinamento e estabelecimento de rotas de fuga para garantir comportamento adequado, pois de nada adiantam recursos tecnológicos sem pessoas que possam agir preventivamente. Reduzir riscos significa segurança e qualidade institucional.

Descritores: Sistemas de Combate a Incêndio; Arquitetura Hospitalar; Recursos Humanos de Enfermagem no Hospital.

\section{ABSTRACT}

This study analyzes the knowledge and conduct of nursing professionals regarding hospital fire prevention, combat and escape. A descriptive study conducted in a public teaching hospital in Goiânia/GO, Brazil, with 109 nursing professionals. Data was collected in 2011 using structured interviews with questionnaires, and descriptive statistics for analysis. Most subjects were female, nursing technicians/assistants (67.9\%), knew the Fire Department's number (85.3\%) and the extinguisher's location (80.7\%), but ignored how they functioned (69.7\%). Also, $57.8 \%$ of interviewees ignored the exit routes and, in case of fire, would alert the fire department, guide people towards the exit, use the extinguisher or jump out of the windows. The gaps identified in this study indicate that in order to guarantee adequate conduct, fire training is necessary, as is the establishment of escape routes, since technological resources are useless without individuals who can act preventively. Risk reduction implies in institutional safety and quality.

Descriptors: Fire Extinguishing Systems; Hospital Design and Construction; Nursing Staff, Hospital.

\section{RESUMEN}

Se objetivó analizar el conocimiento y conducta de profesionales de enfermería sobre prevención, combate y escape de incendios hospitalarios. Estudio descriptivo, realizado en hospital público de enseñanza en Goiânia/GO, con 109 profesionales de enfermería. Datos recolectados en 2011 mediante entrevistas estructuradas con cuestionario, analizadas según estadística descriptiva. A mayoría de los entrevistados era de sexo femenino, técnicos/auxiliares de enfermería (67,9\%), conocía el teléfono del Cuerpo de Bomberos $(85,3 \%)$ y la ubicación de los extintores $(80,7 \%)$, aunque no sabía utilizarlos (69,7\%). La mayoría del personal entrevistado desconocía la ruta de fuga $(57,8 \%)$ y, en caso de incendio, accionaría bomberos, orientaría personas hacia la salida, utilizaría el extintor o saltaría por ventanas. Las carencias identificadas indican necesidad de entrenamiento y establecimiento de rutas de fuga para garantizar comportamientos adecuados, pues de poco sirven los recursos técnicos sin personas que puedan actuar preventivamente. Reducir riesgos significa seguridad y calidad institucional. Descriptores: Sistemas de Extinción de Incendios; Arquitectura y Construcción de Hospitales; Personal de Enfermería en Hospital. 


\section{INTRODUÇÃo}

A presença do fogo numa edificação coloca em risco tanto a estrutura física como a vida de seus ocupantes. Mesmo sendo a proteção à vida humana considerada primordial, muitas vezes a segurança contra incêndio é menosprezada, porque investimentos em prevenção e proteção contra ele não exibem resultados imediatos ou mesmo palpáveis ${ }^{(1)}$. É considerado incêndio, o fogo fora de controle ${ }^{(2)}$. Quando o estrago causado pelo fogo é pequeno, no Brasil diz-se que houve princípio de incêndio e não incêndio ${ }^{(1)}$.

Ainda que no Brasil as perdas por incêndios sejam pouco conhecidas ${ }^{(1)}$, os efeitos do fogo podem ser fatais, indicando que as edificações devem ser projetadas e construídas de modo a garantir a proteção humana contra esses efeitos. A maioria dos incêndios em prédios elevados ocorre em edificações onde estão escritórios, hotéis, apartamentos e hospitais ${ }^{(3)}$.

Pouco se conhece em relação ao risco de incêndio em um edifício hospitalar ${ }^{(4)}$. Quando isso ocorre, o abandono do local, mesmo em situações de menor complexidade é sempre preocupante, pois está em risco a vida de alguns, principalmente daqueles em estado crítico e com dificuldade de locomoção ${ }^{(5)}$. Isso indica a necessidade de se promover e reforçar práticas seguras de trabalho, de proporcionar ambientes livres de riscos, de controlar materiais e equipamentos contra a eventualidade de um princípio de incêndio, de sinalização clara das saídas de emergência e treinamento dos profissionais de saúde para uso dos equipamentos de combate a incêndio. De nada adiantam equipamentos sofisticados de prevenção contra incêndio, se não houverem pessoas treinadas e capacitadas, para agirem de maneira rápida e segura. Cada atraso pode ser determinante no desfecho, pois a ação precoce é mais efetiva que as evacuações ${ }^{(1,4,6-7)}$.

A promoção de segurança e prevenção de danos é de responsabilidade da equipe multiprofissional, mas também é dos visitantes, familiares e pacientes ${ }^{(8-9)}$. É a chamada cultura de segurança enfatizada pelo Programa Nacional de Segurança do Paciente instituído pelo Ministério da Saúde brasileiro, que tem por objetivo geral contribuir para a qualificação do cuidado em saúde em todos os estabelecimentos de saúde do território nacional ${ }^{(10)}$.

A proposta deixa claro que a responsabilidade pelas questões de segurança está associada ao saber agir. Cada um deve seguir as práticas de segurança no trabalho, usando de regras e regulamentos anunciados pelo programa de segurança do hospital. Esse programa é desenvolvido pelas Comissões Internas de Prevenção de Acidentes (CIPA), instituídas pela norma regulamentadora NR-5 $5^{(11)}$, com o objetivo de prevenir acidentes e doenças decorrentes do trabalho, de modo a tornar compatível, permanentemente, o trabalho com a preservação da vida e a promoção da saúde do trabalhador. E ainda, deve-se seguir o que está preconizado pela norma regulamentadora NR-32, que estabelece que nas edificações destinadas à prestação de assistência à saúde da população que utilizam e armazenam produtos inflamáveis, o sistema de prevenção de incêndio deve prever medidas especiais de segurança e procedimentos de emergência ${ }^{(12)}$.

Quando se pensa no escape de um incêndio os ocupantes da edificação devem adotar rotas de fuga e saídas de emergência, com características preparadas para atender as necessidades da população que a ocupa. As rotas de fuga são entendidas como meios estruturais para o caminho seguro de qualquer ponto do edifício até a saída final, possibilitando a qualquer pessoa escapar de um edifício comprometido pelo fogo em segurança, independente da ajuda externa ${ }^{(13)}$. Assim, o planejamento e implementação de planos de segurança contra incêndio nas edificações hospitalares devem ser sempre atualizados e de conhecimento de todos os profissionais que ali atuam, pois rotas de fuga mal planejadas, implantadas ou utilizadas, podem agravar o problema da evacuação segura do edifício(14).

Outro fato que deve ser considerado são as diferentes reações que as pessoas apresentam diante de caso de sinistros, quando percebem sua integridade física ameaçada. Em um incêndio, o comportamento mais frequente é a tensão nervosa ou estresse, e a reação de medo, que foge ao controle racional, ou seja, o pânico. Normalmente, as pessoas demoram a reagir diante de uma situação de incêndio, como se estivessem paralisadas nos primeiros minutos, não acreditando que estejam envolvidas numa situação de risco grave ${ }^{(1)}$.

Em geral, quem é presença constante e contínua junto aos pacientes nessa hora é a equipe de enfermagem. Representa a maioria dos trabalhadores no local, tem conhecimento da área física, das saídas, dos meios de comunicação e, principalmente, auxilia na estimativa do número de pessoas (pacientes, familiares e funcionários) que frequentam a unidade. Em recomendações da Secretaria de Defesa Civil brasileira, a enfermagem coordena a equipe de salvamento e evacuação, sendo responsável pelo Plano de Evacuação da edificação em caso de incêndio ${ }^{(15)}$. 
Assim sendo, é pertinente saber o que os profissionais da enfermagem conhecem sobre a prevenção e combate ao princípio de incêndio, se conhecem as rotas de fuga e se receberam algum tipo de orientação sobre como agir em caso de incêndio. O conhecimento sobre como se comporta o maior grupo de trabalhadores do hospital pode favorecer 0 estabelecimento de condutas adequadas que resultem na preservação da vida humana. A cultura de segurança deve incluir profissionais envolvidos no cuidado e gestores que assumam responsabilidade pela sua própria segurança, pela segurança de seus colegas, pacientes e familiares ${ }^{(10)}$, mas o cuidado é objeto do trabalho da enfermagem. Cuidar é se importar; se importar com o resultado do que se faz e com o que deixa-se de fazer.

Este estudo teve por objetivo, analisar o conhecimento e conduta dos profissionais da enfermagem acerca da prevenção, do combate e do escape de incêndios hospitalares.

\section{METODOLOGIA}

Trata-se de um estudo descritivo exploratório realizado em um hospital público de ensino situado em uma capital da região centro oeste brasileira. A instituição possui 270 leitos numa edificação vertical, que atende entre 800 e 1.000 pessoas por dia, encaminhadas pelo Sistema Único de Saúde.

As instalações não têm chuveiros automáticos para extinção de incêndio e, apesar de ter a CIPA constituída, não há treinamento instituído para estabelecer rotas de fuga, nem realização de simulações de combate ao incêndio e abandono de área, nem sinalização de rotas de fuga. Além disso, não há política de gestão de riscos de monitoramento, minimização e prevenção de incêndios.

A seleção da equipe de enfermagem como sujeitos da pesquisa se justificou pelo fato de estar presente e circulando na maioria dos setores da instituição e representar o maior grupo de trabalhadores do local (700 profissionais). Foram convidados a participar como sujeitos da pesquisa todos que estavam na escala de trabalho em julho e agosto de 2011. Foram excluídos aqueles que estavam de férias ou licença médica no período da coleta de dados e recusaram a participar do estudo 80 profissionais. A amostra foi constituída por 109 integrantes da equipe.

Os sujeitos foram abordados aleatoriamente em suas unidades de trabalho e, aqueles que concordaram em participar do estudo, foram entrevistados em local privativo e assinaram o Termo de Consentimento Livre e
Esclarecido, conforme resoluções 196/96 e 466/2012 do Conselho Nacional de Saúde.

Foram realizadas entrevistas estruturadas em todos os turnos, utilizando questionário que incluiu variáveis sociodemográficas (sexo, idade, tempo de trabalho na enfermagem e categoria profissional) e questões objetivas elaboradas a partir das normas de segurança de edifícios hospitalares ${ }^{(6)}$ e referentes ao conhecimento do profissional sobre a prevenção, sobre combate a princípios de incêndio, sobre as rotas de fuga e escape da edificação hospitalar e ainda, sobre a existência de treinamento institucional abordando ações de prevenção e combate de incêndio. Além dessas, o instrumento continha as questões abertas - O que você faz para prevenir princípio de incêndio? O que você faria em caso de incêndio nesse hospital? Em caso de incêndio, como faria seu escape e o escape dos pacientes de sua unidade? A equipe de pesquisadores inclui um integrante do Corpo de Bombeiros, o que facilitou o estabelecimento das questões norteadoras.

Os dados foram analisados usando o programa Statistical Package for Social Science (SPSS), versão 15.0. As variáveis referentes às condutas para prevenção e fuga em caso de incêndio foram agrupadas por similaridade de conteúdo e apresentadas por meio de estatística descritiva. Variáveis contínuas (idade, tempo de trabalho na enfermagem) foram apresentadas por mediana e valor mínimo e máximo.

O projeto foi aprovado pelo Comitê de Ética em Pesquisa Humana do Hospital das Clínicas da Universidade Federal de Goiás, protocolo nº 198/2010.

\section{RESULTADOS}

A idade dos entrevistados variou entre 19 a 64 anos, com mediana de idade de 40 anos. O tempo de trabalho na enfermagem variou entre um e 36 anos. A estratificação das características sociodemográficas estão descritas na Tabela 1.

As respostas dos profissionais sobre o que conhecem a respeito da prevenção de incêndio estão apresentadas na Tabela 2. 
Tabela 1: Características sociodemográficas de 109 integrantes da equipe de enfermagem de um hospital escola. Goiânia, GO, Brasil, 2011.

\begin{tabular}{|c|c|c|}
\hline Características Sociodemográficas & $\mathbf{n}$ & $\%$ \\
\hline \multicolumn{3}{|l|}{ Sexo } \\
\hline Feminino & 86 & 78,9 \\
\hline Masculino & 13 & 11,9 \\
\hline \multicolumn{3}{|l|}{ Idade } \\
\hline $21-38$ anos & 43 & 39,4 \\
\hline $39-56$ anos & 54 & 53,3 \\
\hline$\geq 57$ anos & 08 & 7,3 \\
\hline \multicolumn{3}{|l|}{ Tempo de Trabalho na Enfermagem } \\
\hline $01-10$ anos & 33 & 30,4 \\
\hline $11-20$ anos & 50 & 46,8 \\
\hline$\geq 21$ anos & 25 & 22,8 \\
\hline \multicolumn{3}{|l|}{ Categoria Profissional } \\
\hline Enfermeiros & 35 & 32,1 \\
\hline Técnico / Auxiliar em enfermagem & 74 & 67,9 \\
\hline
\end{tabular}

Tabela 2: Conhecimento de 109 integrantes da equipe de enfermagem de um hospital escola sobre prevenção de incêndio hospitalar. Goiânia, GO, Brasil, 2011.

\begin{tabular}{lcc}
\hline \multicolumn{1}{c}{ Conhecimento sobre prevenção de incêndio } & n \\
\hline Sabe o número do Corpo de Bombeiros & 93 & 85,3 \\
Sim & 14 & 2,8 \\
Não & 02 & 1,8 \\
Não responderam & 33 \\
Sabe utilizar equipamentos extintores de incêndio & 76 \\
Sim & 30,3 \\
Não & 88,7 \\
Sabe onde estão localizados os extintores de incêndio & 17 \\
Sim & 04 \\
Não & 60,7 \\
Não respondeu & 3,7 \\
Conhece a rota de fuga da unidade hospitalar & 42 \\
Sim & 63 \\
Não & 04 \\
Não respondeu & 38,5 \\
Conhece a CIPA & 57,8 \\
Sim & 3,7 \\
Não & 32 \\
Não respondeu & 73 \\
\hline
\end{tabular}

Aqueles que informaram saber utilizar extintores de incêndio, aprenderam em "cursos de direção defensiva, como busca pessoal, com a CIPA e em outra instituição".

Ao serem questionados sobre o que fazem para prevenir um princípio de incêndio, alguns responderam não saber, ou nunca ter pensado sobre o assunto ou evitam comportamentos de risco como evidenciado nas respostas:

...não sei. (E81);

...nada. (E99);

...nunca pensei sobre isso... (E69);

...nada, só evito acender fogo próximo a oxigênio e materiais inflamáveis. (E48); manipulo com cuidado materiais e substâncias inflamáveis, gás, soluções etc. (E13); ...estamos sempre atentos a qualquer indício de curto circuito, vazamento de gás; solicitamos manutenção e avaliação dos mesmos (E76).
As respostas à pergunta "O que você faria em caso de incêndio nesse hospital?" foram diferenciadas, indicando que alguns acionariam o Corpo de Bombeiros e colaborariam com a evacuação dos pacientes:

...acionaria o Corpo de Bombeiros 193 e orientaria as pessoas a se dirigirem às escadas ou rampas para evacuação do prédio e se possível faria o uso do extintor (E56); ...ajudaria a descer os pacientes e evacuar o hospital, depois de chamar os bombeiros no 148"(E83); "...ajudaria a retirada dos pacientes com segurança enquanto o bombeiro apagaria o fogo"(E103); "...avisaria funcionários da manutenção (E11).

Outros entrevistados responderam:

...correria pelas escadas (E71); 
...não sei qual seria a minha reação, tenho muito medo de fogo (E18);

...pularia pela janela (E53);

...não sei(E19).

Ao serem questionados sobre como fariam o próprio escape e dos pacientes em caso de incêndio, a janela foi apontada como opção:

...depende do local do incêndio; esta unidade possui uma única saída e caso o incêndio estiver bloqueando a saída, a janela seria a única opção de fuga (E11).

Outros cuidariam dos pacientes primeiro e depois de si:

...molharia lençóis, cobriria os pacientes e eu, e sairia do hospital as pressas (E23).

Os demais não souberam como proceder ou nunca pensaram no assunto:

...sem o conhecimento das rotas de fuga fica difícil o escape, tanto dos funcionários quanto dos pacientes (E99);

...eu acho que gritaria muito; não sei o que faria, não gostaria de ter essa experiência. (E39);

...não sei como fazer (E02);

...nunca pensei sobre isso (E69);

...não sei, precisamos fazer um treinamento, digo receber um treinamento atual e adequado (E15).

Ao serem questionados sobre a atuação da CIPA mais da metade não soube responder $(52,3 \%)$ e, quanto a treinamentos sobre prevenção e combate a incêndios, $77,1 \%$ referiram não ter recebido qualquer treinamento, mas, $89,9 \%$ gostariam de participar de treinamentos sobre o assunto:

...sugiro treinamento básico (E59);

...temos a necessidade urgente de um treinamento (E91);

...seria muito importante o treinamento e que ele aconteça o mais breve possível (E77); ...realizar treinamento sobre prevenção de incêndio (E109);

...dúvidas muitas; sugestões - treinamento todo semestre em cada unidade do hospital (E61).

\section{DISCUSSÃO}

Os resultados indicam que a maioria dos profissionais entrevistados trabalham na área há mais de 10 anos, o que não justifica o desconhecimento ou desinteresse sobre o assunto, mas pode explicar, na medida em que incêndio em unidades de saúde são pouco frequentes e não é conteúdo enfatizado nos currículos dos profissionais de saúde brasileiros. Mas, há vários anos o assunto é motivo de preocupação expressa em publicações brasileiras ${ }^{(16)}$, com afirmações ressaltando que "a importância do planejamento na área é medida pelos sinistros evitados e não pelos incêndios extintos como - Incêndio se apaga no projeto!". Talvez isso seja modificado pelo crescente interesse pela gestão da qualidade dos serviços de saúde e propostas de gestão de $\operatorname{riscos}^{(1,6,10,12,17)}$. Tem sido considerado que, para prevenir riscos, ações preventivas devem ser sistematizadas e não somente quando ocorrem os fatos; o gerenciamento sistemático de riscos pode ser a melhor maneira de se influenciar na segurança do paciente ${ }^{(18)}$.

Chama a atenção o fato de alguns profissionais desconhecerem o número telefônico de emergência do Corpo de Bombeiros, pois não é conhecimento específico da área da saúde. A consequência desse fato, pode resultar na demora no acionamento do serviço especializado e o aumento do tempo resposta para a chegada do trem de socorro (Viatura de Comando, Viatura de Combate à Incêndio, Viatura de Salvamento e Viatura de Resgate) ao local. Esse tempo deve ser, no máximo, de 12 a 22 minutos (tempo computado entre a recepção do aviso, deslocamento, estabelecimento do socorro e ataque). É o mesmo tempo necessário para que a temperatura do ambiente signifique risco de inflamação generalizada da estrutura predial (flashover), ou seja, risco maior para todos os ocupantes da edificação(19). Mesmo que a estrutura resista ao fogo por tempo determinado, muitas mortes ocorrem em temperaturas inferiores a do colapso estrutural ${ }^{(20)}$.

Outro aspecto relevante é que a maioria dos entrevistados desconhece como manusear o extintor de incêndio o que prejudica a ação rápida, impossibilita debelar um princípio de incêndio e favorece o risco da perda do controle do fogo. Isso pode significar a perda da própria vida. É algo simples de ser feito e a legislação brasileira exige a existência de extintores móveis e hidrantes de parede, além de chuveiros automáticos e detectores de fumaça e calor, distribuídos de acordo com os ocupantes e zonas de risco(6). Essas medidas visam limitar o crescimento e propagação do incêndio, propiciar evacuação segura do edifício, precaução contra o colapso 
estrutural e rapidez, eficiência e segurança nas operações de combate e resgate ${ }^{(1)}$.

De igual maneira, desconhecer as rotas de fuga do próprio local de trabalho, como informaram os entrevistados, é fator preocupante, pois este é um local que contém os parâmetros que podem tornar os usuários mais ou menos suscetíveis aos efeitos de um incêndio: estado de saúde (mobilidade); estado de atenção (enquanto situados na edificação); treinamento para o escape nas situações de início de incêndio(20-21). A rota de escape é considerada a medida mais eficaz para reduzir danos. Deve ter dimensões planejadas para garantir o transporte das pessoas e ser protegidas quanto aos efeitos do incêndio (calor e fumaça) ${ }^{(5-6,20)}$.

A fumaça, o calor e o cheiro, além de características individuais como idade, dificuldade de locomoção parcial ou total, temporária ou permanente, podem influenciar na escolha da rota de fuga. O percurso mais familiar para a saída pode não ser a opção mais segura, o que pode ser minimizado com a orientação de quem trabalha no local e com a sinalização adequada. A equipe deve conhecer a rota normal e ainda conhecer a rota alternativa $^{(5)}$.Talvez seja essa a razão para que alguns serviços recomendem a equipe de enfermagem como responsável para conduzir a evacuação dos pacientes e do pessoal do hospital ${ }^{(1,15)}$.

Independente de quem coordene a evacuação, o treinamento em conjunto familiariza as pessoas para a cadência e movimentação adequada: nunca correr deve ser a principal regra a fim de não contribuir para o fator pânico e desgaste físico desnecessário(1). A maioria das pessoas que sobrevive às situações de incêndio não é a mais jovem e forte, mas a que tem maior tranquilidade e está preparada para agir nessas situações. Esse comportamento é adquirido através de treinamento específico, principalmente no caso de escape em situações de emergência ${ }^{(1)}$.

Isso pode ser facilitado pela disposição manifestada pelos profissionais de enfermagem entrevistados no presente estudo para adquirir conhecimentos e realizar treinamentos na área de prevenção e combate a incêndios no ambiente hospitalar. Além disso,esse grupo tem como facilitador a idade (mediana 40 anos), que é, juntamente com a saúde e capacidade mental, fatores que afetam a capacidade de reação e procedimento para o escape, dependendo da altura da edificação(20).

É preciso ainda levar em consideração que o ser humano reage de maneira diferenciada e lentamente a uma emergência. O National Institute of Standards and Technology publicou o resultado de entrevistas com pessoas que saíram do incêndio no World Trade Center de Nova York, apontando que houve demora em torno de seis minutos para iniciarem a reação, desligando seus computadores, pegando objetos pessoais e fazendo telefonemas, em vez de se dirigirem de imediato para as saídas de emergência(22).

A recomendação de "se proteger e aguardar pelo socorro", que foi referida como resposta de vários entrevistados no estudo sobre o que fariam no caso da vigência do sinistro, seguiu recomendações gerais dos bombeiros que são veiculadas pela mídia. Outros se preocuparam em proteger os pacientes e orientar as pessoas sobre a evacuação, como preconizado em publicações $^{(5,20)}$, que indicam qual deve ser o comportamento dos profissionais que trabalham nas unidades de saúde. Mas o comportamento referido por outros reforça a necessidade de que o assunto deve ser discutido no cotidiano profissional e de se providenciar o treinamento $^{(1,5,20)}$.

O desconhecimento da existência da CIPA pela maioria dos entrevistados pode ser explicado pelo fato dos profissionais da instituição possuírem diferentes vínculos empregatícios. Entretanto, a legislação brasileira refere que a CIPA é obrigatória para as empresas que possuam trabalhadores com vínculo empregatício. Seja órgão ou empresa pública onde existam trabalhadores efetivamente com vínculos de emprego regidos pela Consolidação das Leis Trabalhistas (CLT) e outros vínculos estabelecidos, a CIPA deve ser constituída levando-se em consideração o número de empregados efetivamente vinculados ao regime celetista. Além disso, na ação da CIPA para a melhoria das condições de trabalho não pode haver, sob pena de infração à Constituição Federal, determinação de medidas discriminatórias, como por exemplo, a solicitação de treinamento ou distribuição de determinado equipamento somente para os celetistas. O dimensionamento da CIPA, deve considerar todos os trabalhadores do estabelecimento, tanto celetistas quanto estatutários ${ }^{(11)}$.

Enfim, considerando que a equipe de enfermagem tem maior possibilidade de identificar o princípio de um incêndio hospitalar é fundamental que esse assunto seja inserido nas discussões atuais que abordam aspectos técnicos da assistência direta e procedimentos das equipes sobre prevenção de infecções e eventos adversos. Essas discussões permitem direcionar o discurso da pesquisa sobre segurança atual para uma "assistência mais segura no amanhã"(23). 


\section{CONCLUSÕES}

Os resultados indicam que há lacunas no conhecimento dos profissionais de enfermagem sobre a prevenção, combate e escape de edificações hospitalares em caso de incêndio, sendo necessário melhorar o conhecimento deles sobre essa possibilidade. Afinal, o risco é grande quando as ações são individuais, desorganizadas e tomadas em momentos de tensão, com desconhecimento dos objetos e requisitos funcionais de segurança. A indecisão sobre como agir pode pesar e infelizmente ser decisiva para a própria perda de vida.

É preciso lembrar que esse evento não é esperado pelos pacientes que lá procuram refúgio para suas enfermidades, e que, o pânico e a perda do controle da situação podem ser mais maléficos que o próprio incêndio.

Um aspecto positivo encontrado nas respostas e que pode facilitar qualquer atividade educativa foi a motivação demonstrada pelos participantes em aprender, pois parecem ter sido surpreendidos pelo fato de não saber como se portar numa eventualidade. $\mathrm{Na}$ realidade, o conhecimento deve ser continuado, de

\section{REFERÊNCIAS}

1. Seito AI, Gill AA, Pannoni FD, Ono R, Silva SB, Carlo UD et al. A segurança contra incêndio no Brasil. São Paulo: Projeto; 2008. 2. Associação Brasileira de Normas Técnicas. NBR 13860. Glossário de termos técnicos relacionados com a segurança contra incêndio. Rio de Janeiro; 1997. 10p.

3. Hall Jr J. High-rise building fires report - september 2013.Quincy, MA: National Fire Protection Association (NFPA); 2013. 43p.

4. Rocha CM. Critérios para dimensionamento de brigada de incêndio em uma unidade hospitalar: estudo de caso. [monografia].Medianeira: Universidade Tecnológica Federal do Paraná; 2012.

5. Damasceno MCT, Ribera JM, Reche AGP, Casassa M. Plano de abandono de hospitais.São Paulo: Secretaria de Estado da Saúde. Governo do Estado de São Paulo; 2012.

6. Agência Nacional de Vigilância Sanitária. Resolução - RDC no 50, de 21 de fevereiro de 2002. Dispõe sobre o regulamento técnico para planejamento, programação, elaboração e avaliação de projetos físicos de estabelecimentos assistenciais de saúde.Brasília; 2002.

7. Agência Nacional de Vigilância Sanitária. Segurança no ambiente hospitalar Brasília; s/d.

8. Consórcio Brasileiro de Acreditação- CBA (Brasil). Padrões de acreditação da Joint Commission International para hospitais. Manual de acreditação. 2010. 228p.

9. McCannon C, Hackbarth A, Griffin F. Miles to go: an introduction to the 5 million lives campaign. Jt Comm J Qual Patient Saf. 2007;33(80):477-84.

10. Ministério da Saúde. Portaria n 529, de $1^{\circ}$ de abril de 2013. Institui o Programa Nacional de Segurança do Paciente (PNSP).Brasília: Diário Oficial da União; 2013.

11. Ministério do Trabalho e Emprego. Norma Regulamentadora 05 - Comissão Interna de Prevenção de Acidentes (CIPA). Norma Regulamentadora aprovada pelo Decreto Legislativo $\mathrm{n}^{\circ} 2$ de 17 de março de 1992.Brasília: Ministério do Trabalho e Emprego; 1992. maneira que não seja cobrado dos profissionais, o comportamento para algo que não foram treinados.

Acreditamos que os resultados obtidos nesse estudo possam instigar programas de educação continuada, além de estimular a discussão sobre essa temática na instituição e nos cursos de graduação em enfermagem. $\mathrm{Na}$ realidade, informações dessa natureza deveriam ser estendidas de forma sistemática a cada estudante, pois fortaleceria sua responsabilidade como cidadão. $\mathrm{Na}$ ocorrência de catástrofes tendemos a procurar culpados, quando na realidade há grande envolvimento de atitudes individuais de respeito ao outro e à vida.

Ainda que possa ser considerada a regra básica da segurança pessoal primeiro, fica sempre na mente que a enfermagem cuida de pessoas que dependem exclusivamente de sua atuação. Porém, essa indecisão sobre como agir pode pesar e ser decisiva para a própria perda de vida. Por isso, são essenciais as estratégias, produtos e ações direcionadas aos gestores, profissionais e usuários da saúde sobre segurança do paciente em situações de incêndio.

12. Ministério do Trabalho e Emprego. Norma regulamentadora 32. Segurança e saúde no trabalho em serviços de saúde. Portaria GM n.0 1.748, de 30 de agosto de 2011.Brasília: Ministério doTrabalho e Emprego; 2011.

13. Ornstein SW, Ono R, Lopes ME, AA. G. Healthcare architecture in São Paulo, Brazil: evaluation accessibility and fire safety in large hospitals. International Journal of Architectural Research. 2007;1(1):13-25.

14. Alves ABCG. Incêndio em edificações: a questão do escape em prédios altos em Brasília-DF. [dissertação].Brasília: Universidade de Brasília; 2005.205p.

15. Ministério da Integração Nacional. Secretaria Nacional de Defesa Civil. Secretaria Nacional de Defesa Civil. Manual de Medicina de Desastres Brasília: Ministério da Integração Nacional. 3 ed; 2007. 91p.

16. Ministério da Saúde. Secretaria de Assistência à Saúde. Série Saúde \& Tecnologia. Textos de apoio à programação física dos estabelecimentos assistenciais de saúde - condições de segurança contra incêndio.Brasília; 1995. 107p.

17. Gama Z, Saturno P. A segurança do paciente inserida na gestão da qualidade dos serviços de saúde. In: Agência Nacional de Vigilância Sanitária, editor. Assistência segura: uma reflexão teórica aplicada à prática.2013. p. 29-40.

18. Hinrichsen SL, Oliveira CLF, Campos MA, Possas LCM, Sabino G, Vilella TAS. Gestão da qualidade e dos riscos na segurança do paciente: estudo-piloto. RAHIS - Rev Administração Hospitalar e Inovação em Saúde. 2011(7):10-7.

19. Corpo de Bombeiros Militar do Estado do Rio de Janeiro [Internet]. Rio de Janeiro: [acesso em: 30 out 2011].Tática de combate a incêndio em edifícios elevados. 2004 - Disponível em: http://www.cbmerj.rj.gov.br/index.php?option=com_content\&vie $\mathrm{w}=$ article\&id=169:tatica-de-combate-a-incendio-em-edificioselevados\&catid=7: Informacoes-Tecnicas\&Itemid=15. 20. Rezende MF. Análise do risco global de incêndio em edifícios hospitalares - diagnóstico de risco da Santa Casa de Misericórdia de São João Del Rei/MG, Brasil. [dissertação]. Ouro Preto: Universidade Federal de Ouro Preto; 2008. 
21. Gouveia AMC, P. E. Tempo de escape em edificações: os desafios do modelamento de incêndio no Brasil. Rem: Rev. Esc. Minas. 2002;55(4):257-61.

22. Moncada J. Caos o pánico... Qué pasa durante el processo de evacuación em um incêndio? . National Fire Protection Association - NFPA. 2005(jul/agos):4.

23. Silva AEBC. Segurança do paciente: desafios para a prática e a investigação em Enfermagem. Rev. Eletr. Enf. [Internet]. 2010 [acesso em: 10 nov 2012]; 12(3): 422. Disponível em:

http://www.fen.ufg.br/revista/v12/n3/v12n3a01.htm.

Artigo recebido em 24/06/2013.

Aprovado para publicação em 21/03/2014.

Artigo publicado em 30/06/2014. 